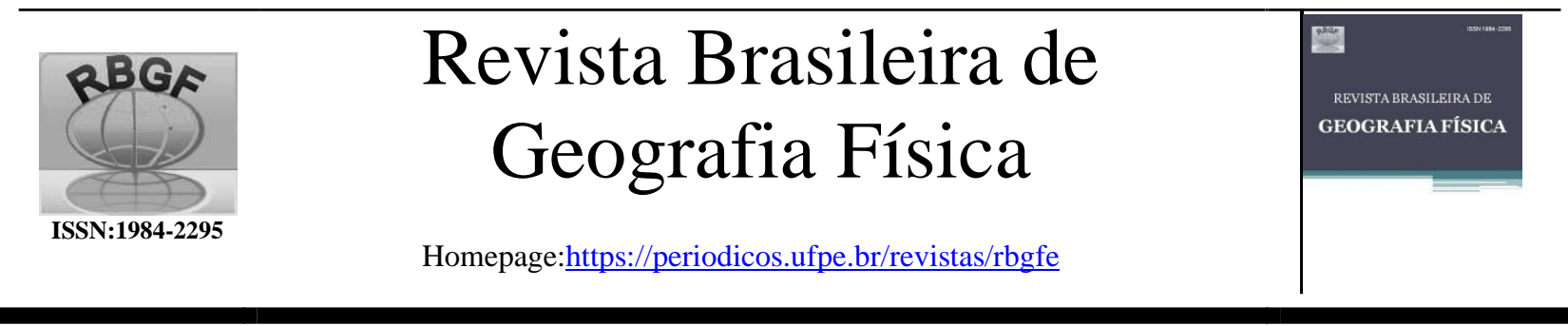

\title{
Vulnerabilidade à erosão hídrica do solo, bacia hidrográfica do rio Araguaia
}

Dênis José Cardoso Gomes ${ }^{1}$, Édria Valdenice Santos de Sousa ${ }^{2}$, Nedilson Sanches Ferreira ${ }^{3}$, Richard Reno da Costa Lobato $^{4}$, Bárbara Farias Ribeiro ${ }^{5}$, Gustavo Francesco de Morais Dias ${ }^{6}$

\begin{abstract}
${ }^{1}$ Mestrando em Ciências Ambientais, Programa de Pós-Graduação em Ciências Ambientais (PPGCA), Universidade do Estado do Pará (UEPA). Email: deniss.feg@gmail.com, CV: http://lattes.cnpq.br/1987185580532060. ${ }^{2}$ Mestranda em Meteorologia, Programa de Pós-Graduação em Meteorologia (PPGMET), Universidade Federal de Santa Maria (UFSM). E-mail: edrya.sousa@gmail.com, CV: http://lattes.cnpq.br/9056150616878479. ${ }^{3}$ Graduando em Meteorologia, Universidade Federal do Pará (UFPA). E-mail: nedilsonlive@ gmail.com. CV: http://lattes.cnpq.br/0727207158085112. ${ }^{4}$ Mestrando em Meteorologia, Programa de Pós-Graduação em Meteorologia (PPGMET), Universidade Federal de Santa Maria (UFSM). E-mail: richardlobato7@gmail.com. CV: http://lattes.cnpq.br/1215292772099185. ${ }^{5}$ Mestranda em Ciências Ambientais, Programa de Pós-Graduação em Ciências Ambientais (PPGCA), Universidade Federal do Pará (UFPA). E-mail: barbaraoc3@gmail.com, CV: http://lattes.cnpq.br/3865723325176938. ${ }^{6}$ Docente do Instituto Federal do Pará. Doutorando em Desenvolvimento Sustentável, Programa de PósGraduação em Desenvolvimento Sustentável no Trópico Úmido, Universidade Federal do Pará (UFPA). E-mail: gustavo.dias@ifpa.edu.br. CV: http://lattes.cnpq.br/7676261135100355
\end{abstract}

Artigo recebido em 16/01/2021 e aceito em 23/05/2021

R E S U M O

O entendimento dos efeitos climáticos e do uso do solo em conjunto é crucial para análise ambiental e prevenções de desastres naturais. O objetivo deste trabalho é analisar a vulnerabilidade à erosão hídrica do solo na bacia hidrográfica do rio Araguaia. Usou-se dados de precipitação (Agência Nacional das Águas); uso e ocupação da terra (Projeto MapBiomas); declividade (Instituto Nacional de Pesquisas Espaciais) e de solo (Empresa Brasileira de Pesquisas Agropecuária) no cálculo de mapas através do geoprocessamento para obter-se a representação da erosão hídrica do solo. A bacia hidrográfica do rio Araguaia caracteriza-se na maior parte por zonas de transição de estabilidade e vulnerabilidade, porém destaca-se as áreas estáveis nas proximidades da foz, regiões críticas á sudoeste (Rio das Mortes), nos limites (leste) do Alto Araguaia, nas partes sudeste e sudoeste do Baixo Araguaia. Na escala climática, a precipitação não apresenta riscos significativos. No entanto, o intenso uso e ocupação da terra na região foi a forçante que maior agravou a vulnerabilidade, principalmente em áreas (declives e solo) naturalmente instáveis. Assim, algumas cidades precisam estar em alerta para possíveis eventos erosivos.

\section{Vulnerability to soil water erosion, Araguaia basin river}

\begin{abstract}
A B S T R A C T
The Understanding climate effects and land use together is crucial for environmental analysis and natural disaster prevention. The objective of this work is to analyze the vulnerability to soil water erosion in the hydrographic basin of the Araguaia river. Rainfall data (National Water Agency) was used; land use and occupation (MapBiomas Project); slope (National Institute for Space Research) and soil (Brazilian Agricultural Research Corporation) in the calculation of maps through geoprocessing to obtain the representation of soil water erosion. The hydrographic basin of the Araguaia river is characterized in the most part by transition zones of stability and vulnerability, however the stable areas in the vicinity of the mouth stand out, critical regions to the southwest (Rio das Mortes), on the (eastern) limits of the Alto Araguaia, in the southeast and southwest parts of the Lower Araguaia. On the climate scale, the rainfall does not present significant risks. However, the intense use and occupation of land in the region was the forcing that increased the risk, mainly in naturally unstable areas (slopes and soil). Thus, some cities need to be alert to possible erosive events.
\end{abstract}

\section{Introdução}

Desastres naturais são efeitos causados pela combinação de fenômenos (hidroclimáticos, biológicos e geológicos) e uso da terra inadequado, no qual atingem zonas urbanas e rurais, provocando perdas humanas e materiais que excedem a capacidade de auto-recuperação da sociedade local, exigindo o auxílio de autoridades Gomes,D.J.G.C., Sousa, E. V.S., Ferreira, N. S., Lobato, R. R. C., , Ribeiro, B. F., Dias, G. F. M. externas (Mata-Lima et al., 2013). Nos últimos anos, os desastres naturais afetaram negativamente a sociedade (Katarine et al., 2014; Barnes et al., 2019)

A precipitação pluvial é um dos principais catalizadores de adversidades, pois através do seu excedente e/ou escassez pode provocar impactos na 
economia, como por exemplo no setor do agronegócio (Casaroli et al., 2018) que pode ser afetado pelas perdas de solo devido a erosividade. Além disso, a precipitação na região tropical é considerada como uma componente meteorológica de alta variabilidade espaço-temporal (Amorim et al., 2020), por isso em área marcadas por extremos climáticos são mais suscetíveis aos impactos negativos promovido por chuvas intensas.

Tadesse et al. (2017) comentam o quanto os problemas ambientais estão preocupando a sociedade mundial através da degradação do solo. E ainda reiteram que a erosão é o principal catalizador para a baixa eficiência agrícola devido a diminuição da qualidade do solo. Na mesma linha de pensamento, Panagos et al. (2015) complementam que a erosão do solo está entre as 8 maiores ameaças ao solo, sendo responsável parcialmente em impactos negativos no setor alimentício, qualidade da água, assoreamento de rios, equilíbrio de ecossistemas, pois afeta o ciclo hidrológico (Stroosnijder, 2007). Para Tominaga et al. (2009), a erosão do solo é um tipo de fenômeno que provoca eventos de desastres naturais, sendo controlada por ações antrópicas e variações climáticas (Sidle et al., 2004).

Este cenário está associado ao conflito dos interesses políticos e econômicos com a forma de exploração, geralmente não sustentável, dos recursos do meio ambiente (Zamparoni, 2012; Ionita et al., 2015), em que o aumento da demanda por alimentos prevista para as próximas décadas (Sposito, 2013) pode intensificar os processos erosivos, colocando em risco a produção agrícola e a segurança alimentar (Vanwalleghem et al., 2017; Mohammed et al., 2020). Souza Jr. et al. (2020) corrobora revelando por meio dos cenários de uso e cobertura do solo, do Google Earth Engine, a retirada de aproximadamente 71 milhões de ha. vegetação nativa no Brasil, sendo o setor do agronegócio o principal responsável. No cerrado, houve cerca de 24,7 milhões de ha. de desmatamento (Alencar et al. 2020), indicando que possíveis consequências ao meio ambiente com tamanha alteração, devido o bioma ser marcado pelas práticas agropastoris como evidenciado por Maciel et al. (2020). Contudo, há relatos de que o fato do Cerrado ser um bioma subvalorizado em relação a Amazônia faça com que este ambiente, rico em recursos naturais não receba a intervenção necessária para monitorar e diminuir as intensas modificações do uso e cobertura da terra (Pires et al., 2020).

De acordo com Merten e Minella (2013) apesar das atividades agrícolas proporcionar aumento nos montantes econômicos do Brasil, o avanço destas práticas geralmente promovem alteração no ciclo hidrológico (Lee et al., 2018; Cavalcantes et al., 2019) e intensificação dos processos erosivos do solo através do escoamento superficial (Shanshan et al., 2018; Gao et al., 2020). A taxa de erosão hídrica do solo brasileiro foi estimada variando entre 600 e 800 milhões de toneladas por ano, e mesmo com a falta de informações sobre qual tipo de uso da terra contribui mais para a degradação do solo, há um consenso científico de que as áreas de pasto no cerrado brasileiro estão bastantes degradadas (Merten; Minella, 2013). Ribeiro e Campos (2007) sugerem que além do pasto, as áreas de agricultura, quando não tratada de modo sustentável, são possivelmente ainda mais danosos ao solo.

Sartori et al. (2019) aponta que há perdas econômicas na escala de 40 á 490 bilhões de dólares variando de país. Conforme Telles et al. (2011) em suas pesquisas estima o impacto econômico negativo promovido pela erosão do solo como nos Estados Unidos com cerca de 44 bilhões de dólares/ano, nos países da União Europeia com aproximadamente 45,4 bilhões de dólares/ano e no Brasil, apenas no estado do Paraná o prejuízo é em torno de 245 milhões de dólares/ano. De acordo com Lense et al. (2019), o Brasil é o maior produtor e exportador de café do mundo, sendo esta atividade fundamental no âmbito socioeconômico como a geração de empregos. Assim, os pesquisadores discutem os prejuízos provocados pela erosão hídrica que promove a perda de toneladas de solos e um déficit financeiro em torno de 6,6 bilhões de reais ao ano e ainda sugerem o uso de Sistemas de Informações Geográficas (SIG) na análise espacial de áreas suscetíveis á erosão para auxiliar na prevenção desses problemas agrícolas. Na mesma linha de raciocínio, Pasinato et al. (2018) afirmam que a região do cerrado apresenta potencial para crescimento das atividades agrícolas, isto foi confirmado por Gomes et al. (2019) que descobriu fatos alarmantes sobre o cerrado, no qual revela a perda de milhões de ha. para o setor agrícola, além de sugerir o uso da geotecnologia para auxiliar no diagnóstico e prevenção de tais problemas ambientais (Barbosa et al., 2018). Bessa et al. (2011) mostrou a importância da região do Araguaia mapeando e descrevendo as usinas hidrelétricas em operação. Reis et al. (2020) reforça em sua pesquisa a importância do entendimento da variabilidade pluviométrica e seus efeitos no regime fluvial da bacia do Araguaia, sugerindo possíveis impactos ambientais que a chuva pode ocasionar. E vale ressaltar que a análise ambiental da vulnerabilidade a erosão do solo é imprescindível para a gestão e 
planejamento de usinas hidrelétricas, pois o assoreamento dos rios e lagos adjacentes as suas instalações podem diminuir a eficiência deste empreendimento fundamental para a manutenção estrutural da sociedade (Pereira, 2014).

Uma forma de analisar a erosão do solo em uma bacia hidrográfica é calculando e geoespacializando a vulnerabilidade do solo à erosão (Silva et al., 2019; Gomes et al. 2020). Desta forma, o termo vulnerabilidade engloba várias vertentes de um sistema, podendo ser usado como indicador para avaliar os riscos á exposição e capacidade de resposta, de diversas subáreas que compõe a esfera socioambiental e econômica de uma região, aos efeitos provocados por fatores antrópicos e/ou naturais (Orozco et al., 2020). Por tanto, segundo Cubaiano et al. (2017) o risco ambiental é o potencial de susceptibilidade que uma paisagem apresenta quando sob efeito de atividades antrópicas e/ou naturais. A desestabilização desses geossistemas em equilíbrio devido as pressões antrópicas promovem áreas vulneráveis a processos erosivos, sendo os produtos indicadores de regiões com potencial da fragilidade ambiental fundamental no diagnóstico e medidas de restrições do uso do solo (Peixoto et al., 2018).

Valle et al. (2016) reforçam que informações de produtos confeccionados de ferramentas das geotecnologias a cerca de componentes características da paisagem como declividade, pedologia, precipitação, uso e ocupação da terra são essenciais na gestão ambiental, pois facilitam a avaliação da sensibilidade do meio ambiente diante às influências que perturbam a ordem dos sistemas ambientais como em bacias hidrográficas (Tiburan Jr. et al., 2013; Hoque et al., 2014).

O Conselho Nacional de Recursos Hídricos definiu na Resolução n. 32, de 15 de outubro de 2003 a denominação Regiões Hidrográficas como "o espaço territorial brasileiro compreendido por uma bacia, grupo de bacias ou sub-bacias hidrográficas contíguas com características naturais, sociais e econômicas homogêneas ou similares, com vistas a orientar o planejamento e gerenciamento dos recursos hídricos". O Conselho Estadual de Recursos Hídricos do Pará, por meio da Resolução n. 4, de 03 de setembro de 2008, aplicou o mesmo conceito para o território paraense, com a divisão em 7 Regiões Hidrográficas.

Para Mendes et al. (2018), bacia hidrográfica é um território caracterizado pela drenagem de rio principal e tributários com cabeceira em altiplano, sendo a água pluvial escoada através dos relevos que atuam como divisores hídricos até atingir a foz em áreas mais baixas, além de infiltrar no solo para abastecer nascentes e águas subterrâneas.

A unidade de paisagem definida pelas bacias hidrográficas componentes da Região Hidrográfica do Tocantins-Araguaia (CNRH, Resolução n. 32/2003), destacam-se principalmente pelos seguintes aspectos ambientais (ANA, 2015): degradação dos solos, devido ao uso com finalidades que extrapolam a capacidade de sustentação do sistema, sobretudo nas áreas de intensa atividade agrícola; alteração da qualidade da água pelo uso inadequado das áreas marginais e das planícies de inundação; além de intervenções com obras de engenharia inadequadamente planejadas, favorecendo a ocorrência de processos erosivos; e as modificações na cobertura florestal, devido à exploração não-sustentável da vegetação primária e secundária. Desta forma, o objetivo deste trabalho é analisar a vulnerabilidade à erosão hídrica do solo na bacia hidrográfica do rio Araguaia.

\section{Material e métodos}

Área de estudo

A Bacia Hidrográfica do rio Araguaia (BHA) representada pela Fig. 1 localiza-se no Brasil central drenando quatro estados (Goiás, Mato Grosso, Pará e Tocantins) com uma área de aproximadamente $384.818 \mathrm{~km}^{2}$ e população de cerca de 1.365.220 hab. (MINISTÉRIO DO MEIO AMBIENTE, 2006). A BHA possui sua nascente na região de altos relevos em Serra do Caiapó (Mineiros-GO) e sua foz na confluência com o rio Tocantins, assim é formada pelas sub-bacias: Alto Araguaia (a), Rio das Mortes (b), Cantão do Araguaia (c). Médio Araguaia (d) e Baixo Araguaia (e) (Gomes et al., 2019).

A climatologia da BHA é caracterizada por precipitações médias anuais oscilando de 1.450,0 $\mathrm{mm}$ á 1.850,00 mm, temperaturas médias mínimas e máximas do ar de $22^{\circ} \mathrm{C} \mathrm{e} 35^{\circ} \mathrm{C}$ respectivamente, umidade relativa média do ar de $72 \%$, velocidade e direção do vento de $2 \mathrm{~m} \cdot \mathrm{s}^{-1} \mathrm{NO}$ (INMET, 2020). A BHA possui cobertura vegetal constituída de biomas do cerrado dominando o eixo centro-sul e florestas amazônicas de terra firme concentrandose no Baixo Araguaia que são essenciais na definição do clima regional, além da manutenção do fluxo hídrico e preservação do solo de processos erosivos (MINISTÉRIO DO MEIO AMBIENTE, 2006; Balbinot et al., 2008). 


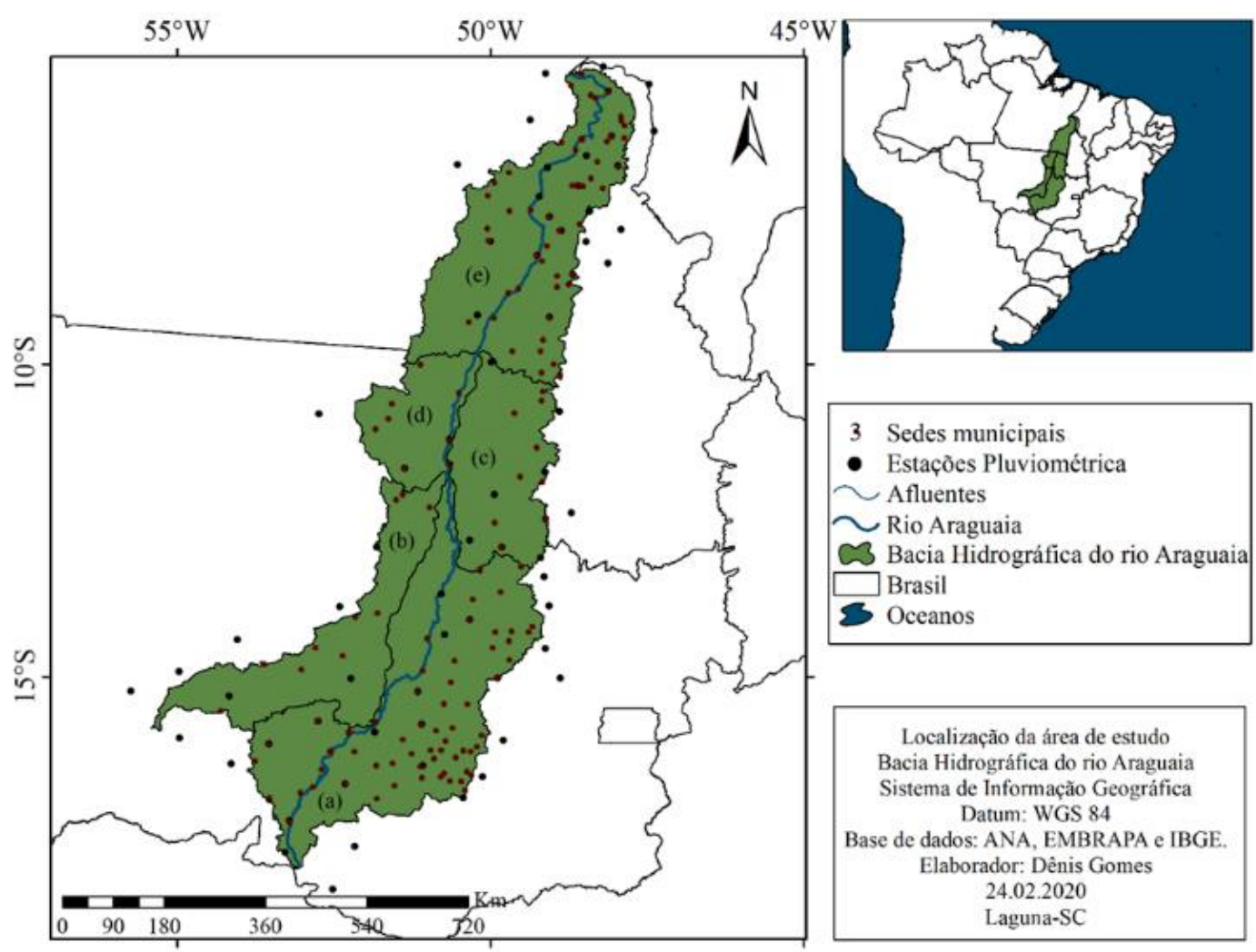

Figura 1. Localização da área de estudo: Bacia Hidrográfica do rio Araguaia: (a) Alto Araguaia; (b) Rio das Mortes; (c) Cantão do Araguaia; (d) Médio Araguaia e (e) Baixo Araguaia. Fonte: ANA (2020); IBGE (2020). Adaptado por autor (2020).

\section{Aquisição e Processamento de dados}

A técnica de geoprocessamento álgebra de mapas foi realizada considerando produtos de espacialização pluviométrica da BHA utilizando dados de 63 pluviômetros distribuídos da ANA (2019), mesmos usados por Gomes et al. (2019); da inclinação do terreno com base nos dados SRTM (INPE, 2020) como feito por Cubaiano et al. (2017); do uso e ocupação da terra (Projeto MapBiomas, 2020) conforme Cassol et al. (2020); da distribuição espacial das classes de solos através dos dados do SiBCS (2018).

$\mathrm{O}$ produto de vulnerabilidade à erosão hídrica do solo é apresentado pela Eq. 1 (Crepani et al., 2001; Ribeiro; Campos, 2007; Matule; Macarringue, 2020):

$$
V=\frac{P+D+U+S}{4}
$$

Onde:

$\mathrm{V}=$ Vulnerabilidade à erosão do solo; $\mathrm{U}=$ Uso e ocupação da terra; $\mathrm{P}=$ Pluviosidade $(\mathrm{mm}) ; \mathrm{S}=$ Solos; D = Declividade (Graus);
A Tab. 1 mostra a relação escalar da vulnerabilidade à erosão hídrica do solo com a classificação ponderada conforme padrões de estabilidade e/ou vulnerabilidade das variáveis em estudo, no qual os pesos foram atribuídos de acordo com a classificação de cada variável considerando o sugerido por Ribeiro e Campos (2007).

Usou-se a metodologia proposta por Crepani et al. (2001), posteriormente por Ribeiro e Campos (2007), Valle (2016), onde foi confeccionado em ambiente SIG através da ferramenta calculador de raster um produto da vulnerabilidade à erosão hídrica do solo influenciado pelas variáveis em análise. $\mathrm{O}$ cálculo (Eq. 1) foi feito em SIG baseando-se nas variáveis ambientais (Precipitação, Uso e cobertura do solo, Declividade e Solos) descritas anteriormente, todas em formato raster, reclassificando cada componente na ferrementa Reclassfy para finalmente realizar a combinação dos dados ambientais adicionando-os na função calculador de raster, obtendo assim a vulnerabilidade à erosão hídrica do solo (Crepani et al., 2001; Ribeiro; Campos, 2007).

Tabela 1. Escala e classificação de Vulnerabilidade à erosão hídrica do solo.

Gomes,D.J.G.C., Sousa, E. V.S., Ferreira, N. S., Lobato, R. R. C., , Ribeiro, B. F., Dias, G. F. M. 


\begin{tabular}{|c|c|c|}
\hline Vulnerabilidade (V) & $\begin{array}{l}\text { Intervalo de } \\
\text { valores }\end{array}$ & Critérios \\
\hline Vulnerável & $V>2,6$ & $\begin{array}{l}\text { Retrabalhamento das formas de relevo } \\
\text { são dominantes }\end{array}$ \\
\hline Moderadamente Vulnerável & $2,2<\mathrm{V} \leq 2,6$ & $\begin{array}{l}\text { Há o retrabalhamento maior das formas } \\
\text { de estabilidade }\end{array}$ \\
\hline $\begin{array}{l}\text { Medianamente } \\
\text { Estável/Vulnerável }\end{array}$ & $1,7<\mathrm{V} \leq 2,2$ & $\begin{array}{l}\text { O padrão de estabilidade e } \\
\text { retrabalhamento das formas de relevo são } \\
\text { próximos }\end{array}$ \\
\hline Moderadamente Estável & $1,3<\mathrm{V} \leq 1,7$ & $\begin{array}{l}\text { Há o retrabalhamento maior das formas } \\
\text { de estabilidade }\end{array}$ \\
\hline Estável & $\mathrm{V}<1,3$ & $\begin{array}{c}\text { A estabilidade das formas de relevo são } \\
\text { dominantes }\end{array}$ \\
\hline
\end{tabular}

\section{Resultados e discussão}

Precipitação

No mapa de distribuição espacial pluviométrica anual (Fig. 2) encontra-se a região do extremo norte caracterizada pelos maiores montantes pluviométricos oscilando de 1.740,9 $\mathrm{mm}$ a $1.834,2 \mathrm{~mm}$. De acordo com registros do Sistema Nacional de Proteção da Defesa Civil (SNPDC, 2020) eventos de chuvas intensas promoveram Situações de Emergências (SE) ao sul da BHA em zonas de baixa pluviosidade nas cidades de Água Boa, Alto Araguaia, Campinápolis, General Carneiro e Novo Santo Antônio; além de Araguaína (norte) em áreas de grandes volumes pluviais. Tais eventos extremos podem estar relacionados a estação chuvosa da região (Gomes et al., 2019).

Na região do Médio Araguaia, ao norte do Cantão do Araguaia e no sul do Baixo Araguaia predominam precipitações na faixa intermediária em torno de $1.601,3 \mathrm{~mm}$ a $1.675,9 \mathrm{~mm}$.

No sul da BHA são observados os menores valores pluviométricos, abaixo de $1.600,0 \mathrm{~mm}$. Com variação de aproximadamente $1.458,1 \mathrm{~mm}$ a $1.599,5 \mathrm{~mm}$. Nesta região, a SNPDC (2020) notificou a ocorrência de estiagens nos municípios de Água Boa, Alto Araguaia, Alto Garças, Caiapônia, Monte Claros de Goiás, Primavera do Leste, Nova Xavantina, Tesouro, Torixoréu; com exceção de Canabrava do Norte e Vila Rica que se situam em regiões de alto regime pluvial. Estes desastres foram em anos marcados por oscilações climáticas dos oceanos adjacentes (Pacífico e Atlântico tropicais) desfavoráveis a precipitação (Serrão et al., 2015), assim como ocorreram na estação seca da região (Gomes et al., 2019), indicando um certo grau de sensibilidade da BHA ás interações oceano-atmosfera.

De acordo com Crepani et al. (2004), a intensidade pluviométrica é a variável mais importante, pois representa a relação entre a quantidade e a distribuição sazonal. Significa dizer que em uma pluviosidade anual elevada, mas distribuída ao longo de todo período anual, o poder erosivo será menor que uma precipitação anual reduzida, mas concentrada em um certo período do ano.

Segundo Gomes et al. (2019) a climatologia desta região da BHA é influenciada por sistemas atmosféricos indutores de precipitação como a Zona de Convergência do Atlântico Sul (ZCAS), Frentes Frias (FF), Massas de $\operatorname{Ar}(\mathrm{MA})$, além dos inibidores de chuva como o Anticiclone Subtropical Semipermanente do Atlântico Sul (ASSAS).

O monitoramento da variabilidade das chuvas e sua intensidade é essencial para a gestão hídrica e avaliação do potencial risco deste elemento atmosférico para a sociedade, prevenindo a ocorrência de desastres naturais (Ashcroft et al., 2019). Piacentini et al. (2018) afirmam que os eventos extremos pluviométricos são um dos principais fatores que induzem a erosão do solo. 


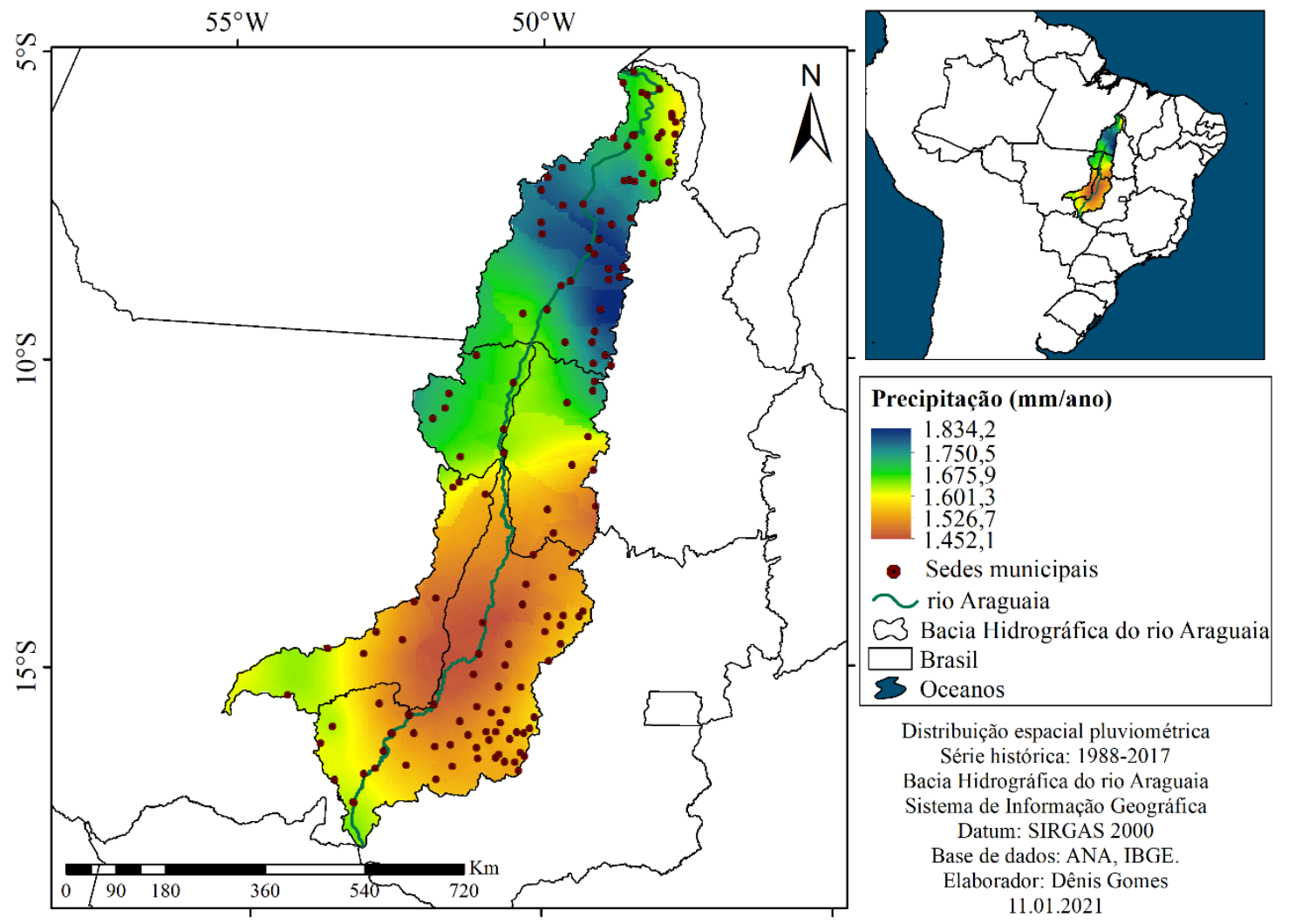

Figura 2. Espacialização pluviométrica anual (1988 - 2017): Bacia Hidrográfica do rio Araguaia. Fonte:

ANA (2019). Adaptado por autor (2020).

A Fig. 3 mostra a vulnerabilidade pluviométrica da BHA. Pode-se observar duas classes, em que na região norte da área predomina zonas de moderadamente estável abrangendo cerca de $41.108,1 \mathrm{~km}^{2}(10,7 \%)$, consequentemente, sendo uma área sujeita a vulnerabilidade imposta pela precipitação, devido o alto índice pluviométrico. Entretanto, o restante da área abrange aproximadamente $343.550,8 \mathrm{~km}^{2} \quad(89,3$ $\%$, apresentando a classe estável, no qual se observaram poucos volumes significativos de precipitação, portanto a área apresenta uma baixa vulnerabilidade.

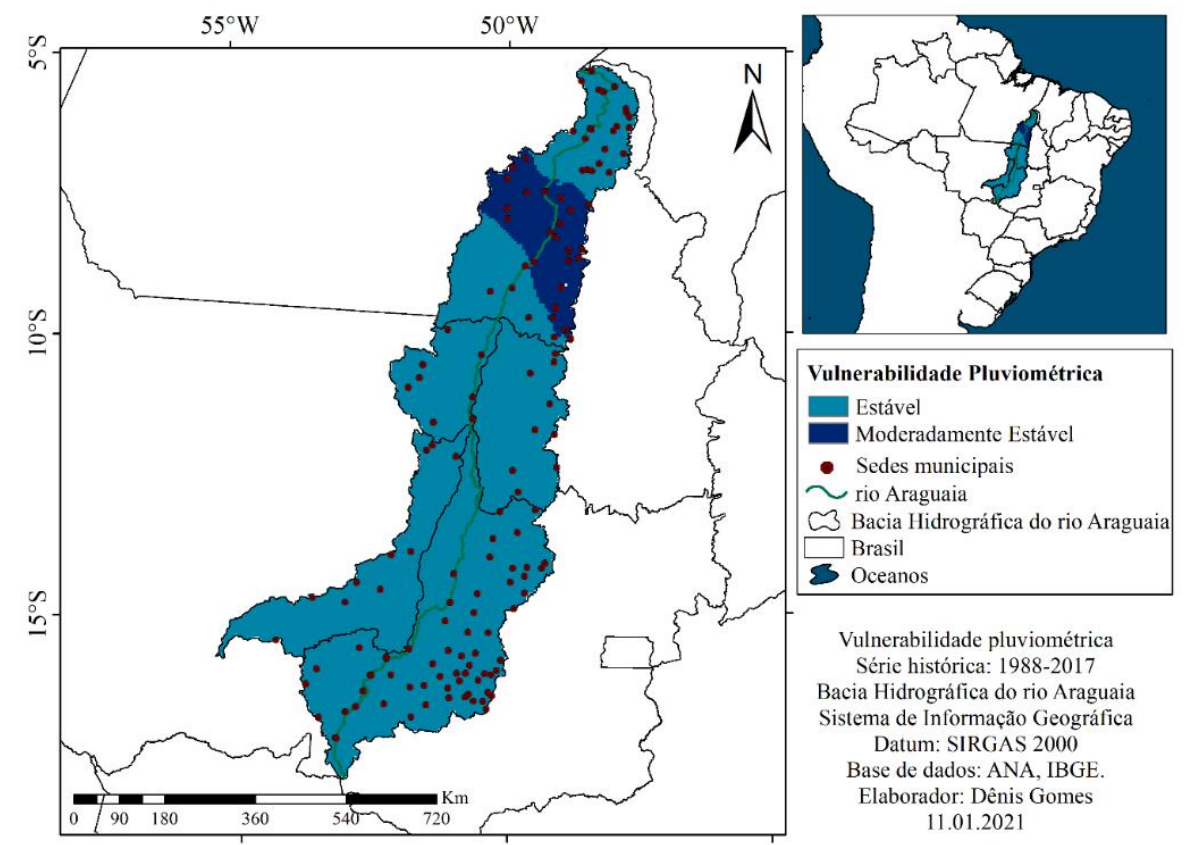

Figura 3. Vulnerabilidade pluviométrica: Bacia Hidrográfica do rio Araguaia. Fonte: Autor (2020).

Gomes,D.J.G.C., Sousa, E. V.S., Ferreira, N. S., Lobato, R. R. C., , Ribeiro, B. F., Dias, G. F. M. 


\section{Uso e ocupação da terra}

O uso da terra na BHA (Fig. 4) é composto por 6 categorias. As áreas de pasto são predominantes compondo 209.995,5 km² (54,5\%) da área, mostrando a grande supressão florestal, assim como vários estudos já apontaram que a região da BHA é marcada nas últimas décadas pela intensa atividade agropastoril (Peron; Evangelista, 2004; Rabelo et al., 2009; Almagro et al., 2017) e reforçada no estudo de Almeida et al. (2018) que mostraram a dominância do pasto na sub-bacia do rio Coco (margem direita do rio Araguaia). Em seguida, as florestas compõem aproximadamente 150.154,0 km² (39,0\%), distribuída ao longo de toda a BHA, porém, de forma mais densa na fronteira à sudeste entre o Baixo Araguaia e o Cantão do Araguaia; sendo o Alto Araguaia a região mais desmatada com grande presença áreas agrícolas e maior concentração de sedes municipais. As áreas de agricultura estão distribuídas principalmente a sudoeste da BHA (Rio das Mortes), com menores porções nas demais sub-bacias e no extremo sul do Alto Araguaia, somando ao todo cerca de $18.373,1 \mathrm{~km}^{2}(4,8 \%)$ do terreno.

O Brasil central, no qual situa-se grande parte da BHA, é fortemente caracterizado pelo seu histórico de uso da terra para a expansão agrícola (Carvalho et al., 2009; Oliveira et al., 2012). A massa d'água que possui uma área de $3.301,7 \mathrm{~km}^{2}$ $(0,9 \%)$ representando o rio Araguaia e seus afluentes mostra a dimensão do quanto este importante sistema fluvial está sob ameaça das atividades antrópicas. Por tanto, pesquisas como de Serrão et al. (2020) que estudaram a região do Tocantins-Araguaia são importantes, pois constataram as mudanças da cobertura da terra provocam alterações no balanço hídrico desta área, mostrando o comportamento da BHA sob os efeitos das ações antropogênicas.

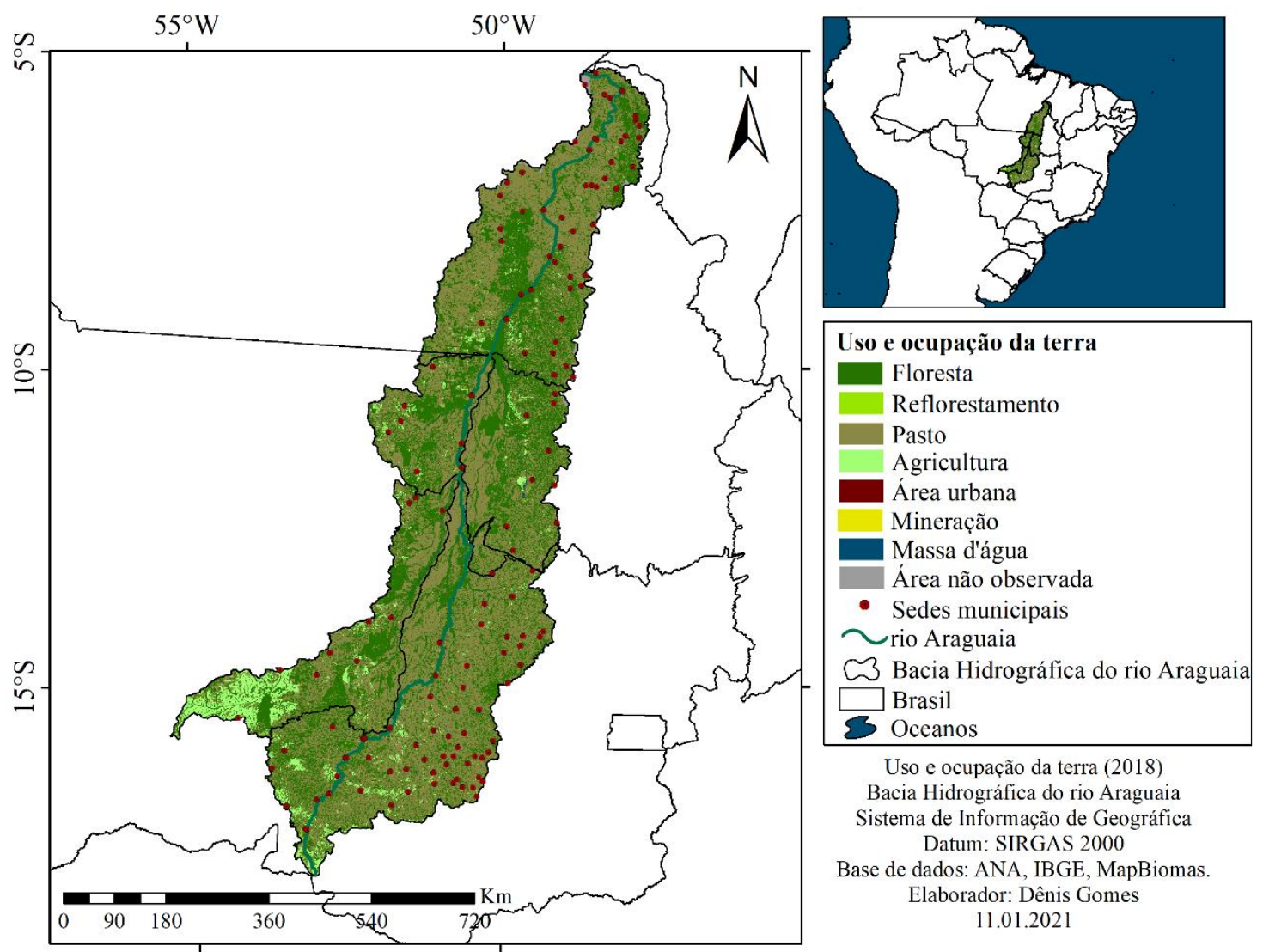

Figura 4. Uso e ocupação da terra: Bacia Hidrográfica do rio Araguaia. Fonte: Projeto MapBiomas (2020). Adaptado por autor (2020).

As áreas urbanas representam $979,5 \mathrm{~km}^{2}$ $(0,2 \%)$, sendo o Alto e Baixo Araguaia as regiões com maiores números de centros habitacionais. Essas duas regiões são marcadas por intensas alterações na cobertura da terra que influenciam de modo negativo na hidrossedimentologia local aumentando processos erosivos fluviais (Assis; Bayer, 2020).

O aumento populacional nos últimos anos acarreta na intensificação da degradação ambiental 
devido a demanda por terrenos, seja para fins habitacionais ou atividades agropastoris, estás áreas destinadas para a geração destes recursos básicos para a subsistência humana como a produção de alimentos estão se expandindo na região do cerrado brasileiro, gerando efeitos negativos no solo quando não tratado corretamente, suscetibilizando o terreno a erosões (Merten; Minella, 2013). E com território espacialmente inferior, são observadas áreas de reflorestamento com 273,9 $\mathrm{km}^{2}(0,07 \%)$, indicando que o reestabelecimento florestal não é uma prioridade nesta região. Áreas pequenas de mineração são identificadas com $8,9 \mathrm{~km}^{2}(0,002 \%)$ ao longo da BHA, além de pontos não observados de aproximadamente $1.904,9 \mathrm{~km}^{2}(0,5 \%)$ da área.

Bayer et al. (2020) constatou mudanças significativas no uso e cobertura do solo na BHA, observando que este fator antrópico está causando degradação ambiental, ratificando a vulnerabilidade da região a erosão do solo devido a conversão da floresta em áreas agropastoris.

De acordo com o trabalho de Borges e Loyola (2020), o prognóstico de 50 anos aponta região do Alto Araguaia estará sob risco devido a pouca vegetação prevista, o que pode afetar negativamente serviços ecossistêmicos e provocar instabilidade no solo. Isto reforça as consequências futuras do uso e ocupação da terra sem planejamento sustentável.

Na Fig. 5 é apresentado a vulnerabilidade ao uso e ocupação da terra, onde observa-se áreas estáveis $151.249,5 \mathrm{~km}^{2}(39,3 \%)$ principalmente no eixo centro-norte e lado oeste, que podem estar associadas a florestas, núcleos urbanos e a mineração; a categoria moderadamente estável com 3.568,2 $\mathrm{km}^{2}(0,9 \%)$ reflete a influência da hidrologia regional e o reflorestamento. Áreas reclassificadas como medianamente estáveis/vulneráveis com $211.805,1 \mathrm{~km}^{2}(55,0 \%)$ são destacadas ao longo de toda a BHA e provavelmente seja os efeitos da pastagem. Entretanto, a região mais crítica está a sudoeste (sub-bacia do rio das Mortes) e pontos no extremo sul, enquadrando-se na categoria vulnerável $18.369,1 \mathrm{~km}^{2}(4,8 \%)$ e sendo possivelmente relacionadas a agricultura.

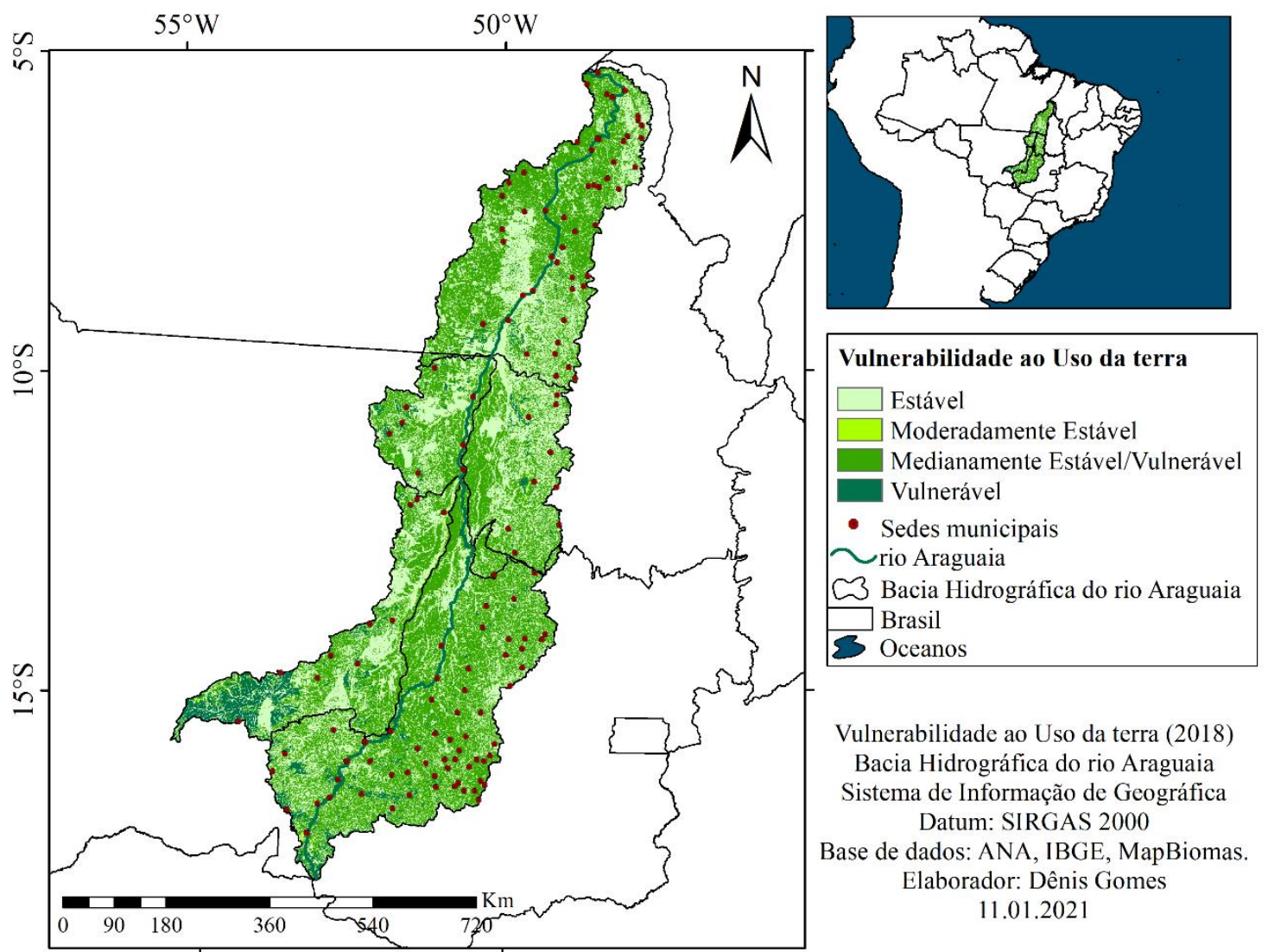

Figura 5. Vulnerabilidade ao uso e ocupação da terra: Bacia Hidrográfica do rio Araguaia. Fonte: Autor (2020).

Declividade
Observa-se a declividade na BHA (Fig. 6), no qual a parte central apresenta as menores inclinações de terreno $\left(0^{\circ}-9^{\circ}\right)$, representado bem 
as planícies de inundações. No entanto, as áreas mais íngremes $\left(12^{\circ}-23^{\circ}\right)$ são nas bordas da BHA com destaque para o sul que é identificado alguns pontos de valores máximos de declive indicando relevos acidentados. Couto Jr. et al. (2021) em seu trabalho mostrou um mapeamento clinográfico similar da BHA. Moreira e Perez Filho (2020) mencionam que o Brasil central é caracterizado pela sua geomorfologia tabular com delimitações abruptas de declives íngremes e geralmente superiores á $6^{\circ}$ como observado na Fig. 6 .

Prina et al. (2016) reiteram que a declividade do terreno afeta na produção agrícola, além de ser essencial na geração de informações a respeito da velocidade de escoamento superficial das águas pluviais, assim como indicador de vulnerabilidade à erosão do solo e movimentos de massa, alertando sobre o inadequado uso e ocupação de áreas comprometidas. Por tanto, tal escoamento hídrico pode ser agravado em inclinações de terreno muito íngremes ocasionando enxurradas, onde através desta há maior desprendimento de partículas do solo suscetibilizando os processos erosivos (Barbosa et al., 2012). Alguns locais onde ocorreu episódios de enxurradas foram em: Alto Boa Vista, Araguaína, Bom Jardim de Goiás, Brejo Grande do Araguaia, Confresa, Floresta do Araguaia, Nova Nazaré, Nova Xavantina, Pau D’arco, Rio Maria, Santa Maria das Barreiras, Santana Do Araguaia, Serra Nova Dourada (SNPDC, 2020).
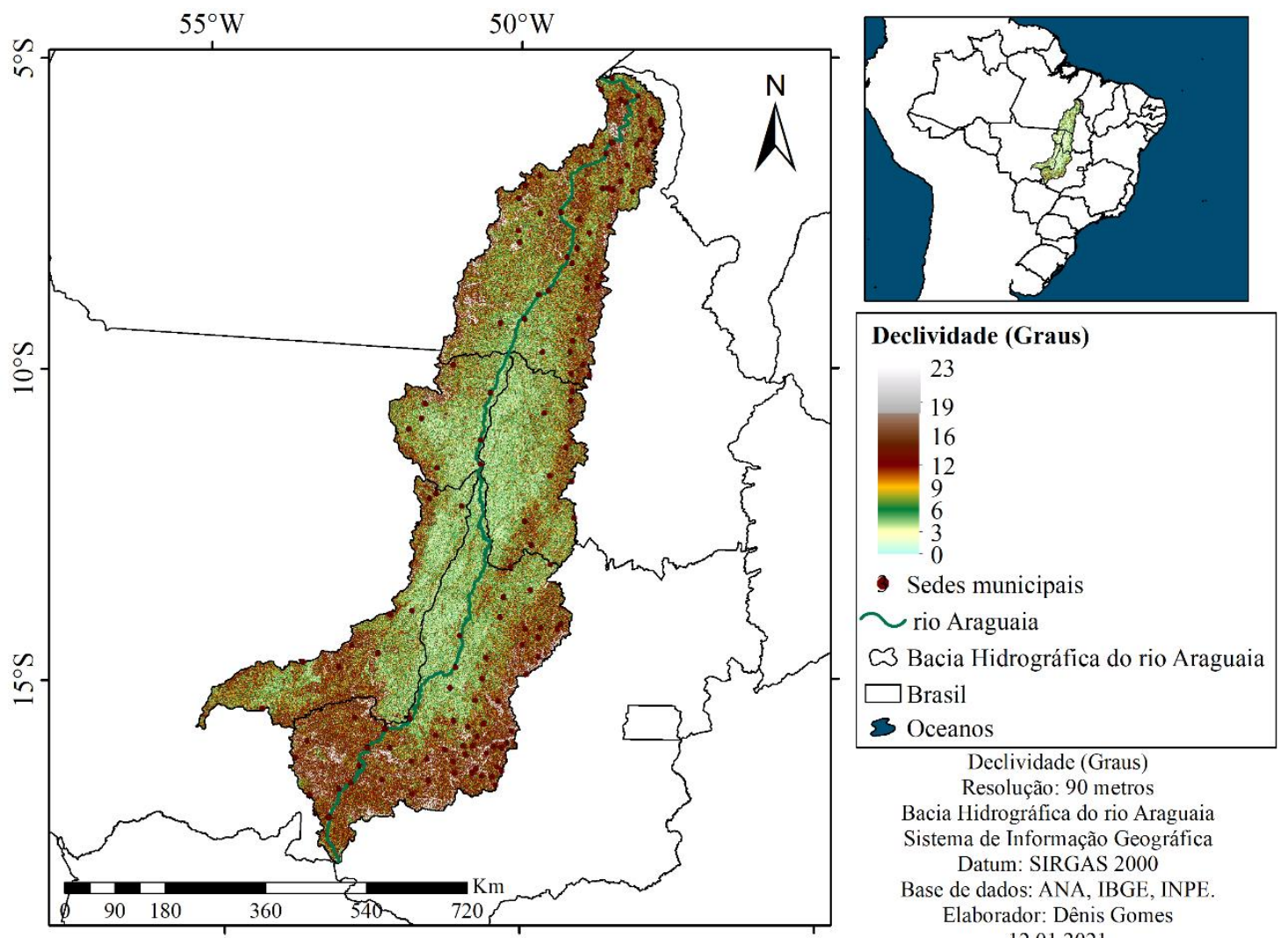

Figura 6. Declividade: Bacia Hidrográfica do rio Araguaia. Fonte: INPE (2020). Adaptado por autor (2020).

A vulnerabilidade clinográfica (Fig. 7) apresenta áreas estáveis $219.226,8 \mathrm{~km}^{2}(56,9 \%)$ em grande parte no centro da BHA e moderadamente estáveis $101.269,5 \mathrm{~km}^{2}(26,3 \%)$ nas proximidades. Regiões classificadas como medianamente estáveis/vulneráveis $39.270,4 \mathrm{~km}^{2}$ $(10,2 \%)$ são observadas adjacentes a fronteira da BHA, assim como as áreas vulneráveis 25.228,3 $\mathrm{km}^{2}(6,5 \%)$ presentes próximas aos limites fronteiriços da BHA. Han et al. (2019) apontam que valores altos de inclinação do terreno é uma das principais causas de perdas de nutrientes do solo. Em Goiás, Silva e Rosa (2019) analisaram variáveis ambientais e ponderaram que quanto maior o grau de declividade associado a solos com alta erodibilidade, maior será a susceptibilidade natural da área a erosão do solo. Estudos no Estado do Mato Grosso identificaram perdas de água (eutrofização) por enxurradas devido a inclinação da superfície terrestre (Leite et al., 2018). 

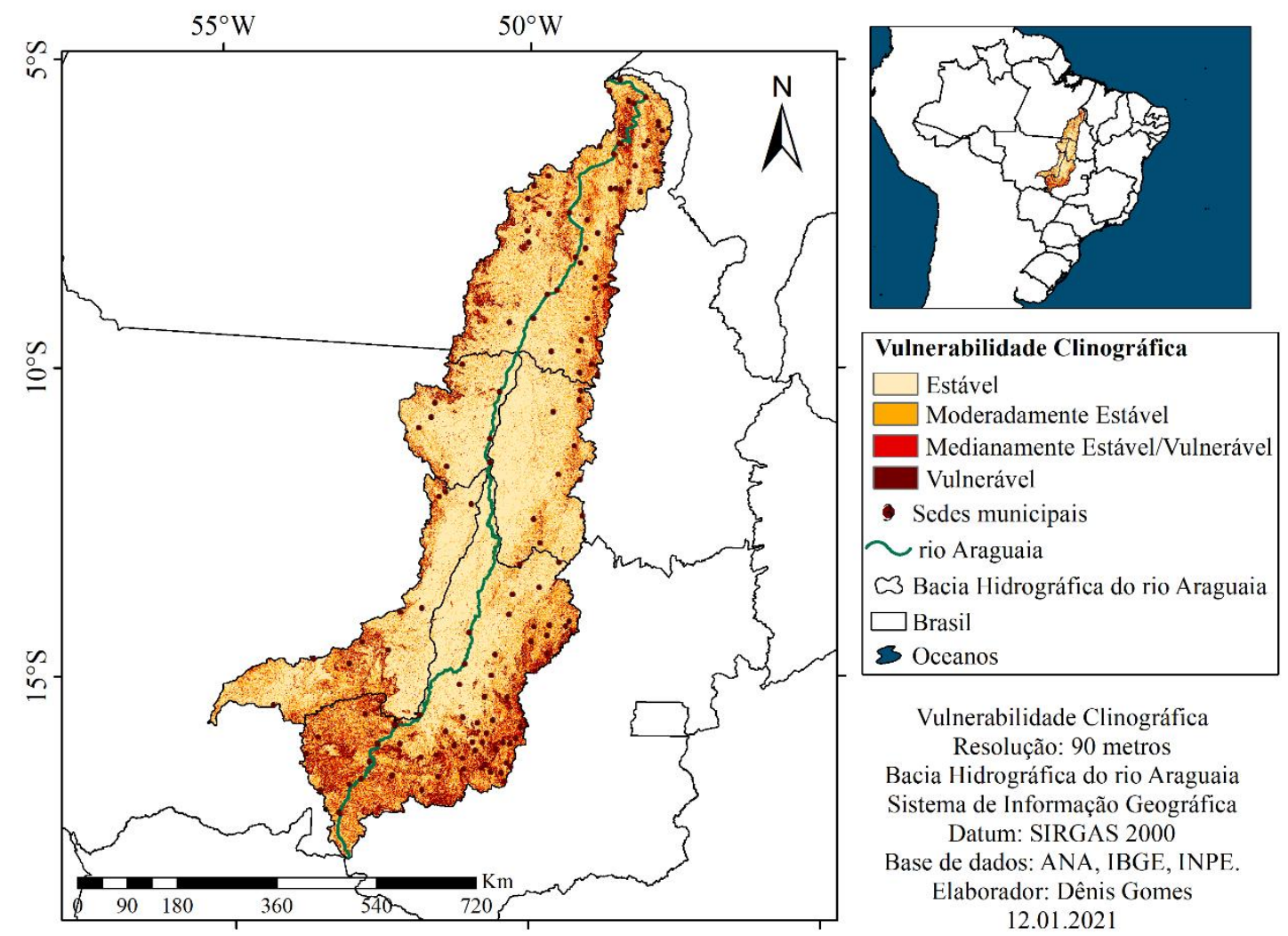

Figura 7. Vulnerabilidade Clinográfica: Bacia Hidrográfica do rio Araguaia. Fonte: Autor (2020).

Solos

Na Fig. 8 é mostrada a distribuição pedológica da BHA, onde há presença do latossolo (sul) e o plintossolo (centro) abrangem as maiores extensões territoriais com $101.146,9 \mathrm{~km}^{2}(26,3 \%)$ e $98.370,4 \mathrm{~km}^{2}(25,5 \%)$ respectivamente. Em seguida, áreas de argilossolo compondo cerca de $82.342,0 \mathrm{~km}^{2}(21,4 \%)$ são identificadas em maior concentração no eixo norte-noroeste. $\mathrm{O}$ neossolo com $47.072,3 \mathrm{~km}^{2}(12,2 \%)$ é observado mais ao sul e com alguns pontos ao norte-noroeste. A região (sul) marcada pela presença do cambissolo que apresenta 26.328,7 $\mathrm{km}^{2}(6,8 \%)$; abrange também áreas de gleissolo com 25.587,6 km² $(6,6$
\%), no qual observa-se sua maior predominância na parte central da BHA, adjacente ao sistema hidrográfico principal mostrado que possui uma área de $2 \cdot 677,7 \mathrm{~km}^{2}(0,7 \%)$. E uma pequena região de chernossolo constitui aproximadamente 1.473,9 $\mathrm{km}^{2}(0,4 \%)$ de superfície territorial, situando-se no extremo norte.

Para Ferreira et al. (2010) a vulnerabilidade do solo a erosão hídrica está relacionada ao tratamento dado as culturas como manuseio e se agrava quando há a retirada da cobertura vegetal, expondo o solo a precipitação provocando processos de erosão hídrica, laminar, sulcos e voçorocas. 

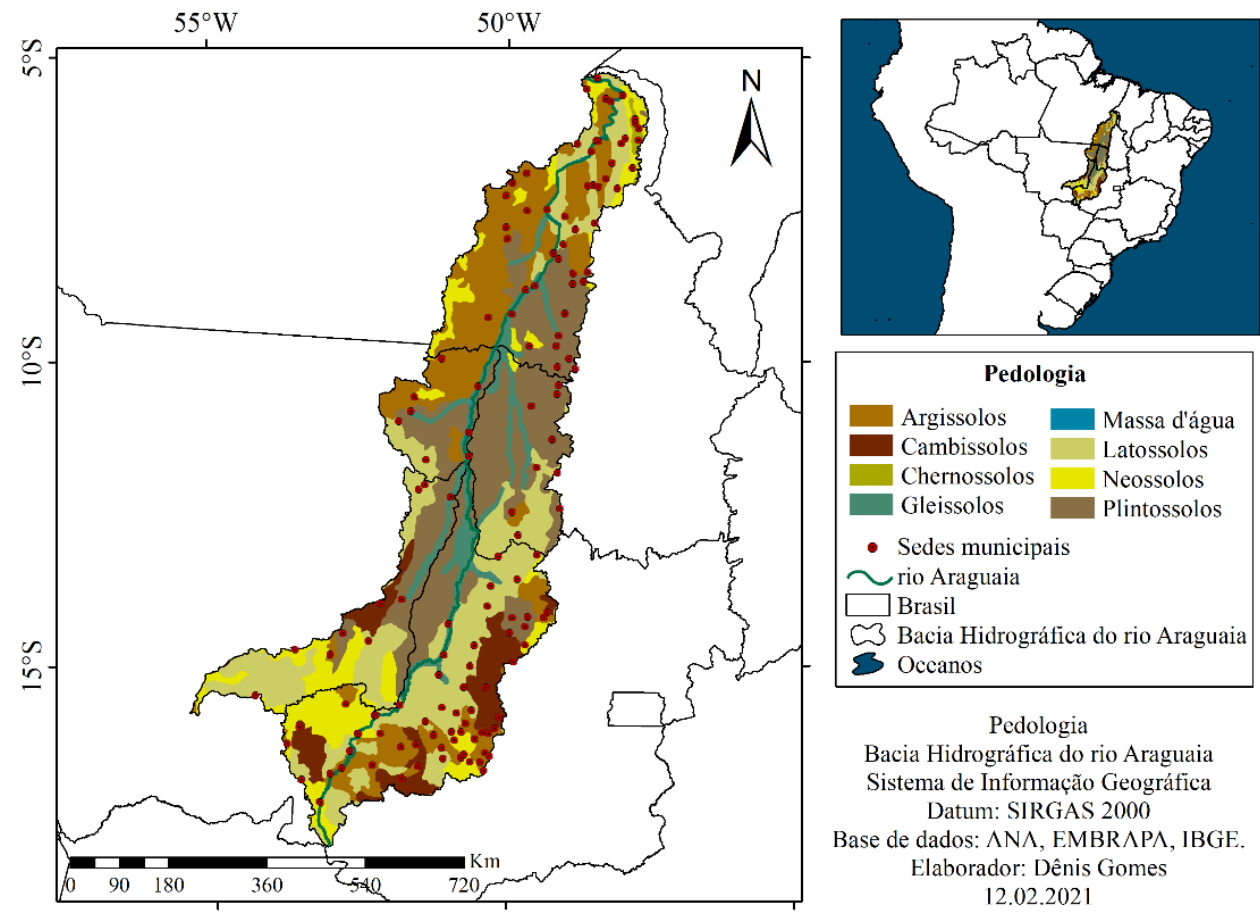

Figura 8. Pedologia: Bacia Hidrográfica do rio Araguaia. Fonte: EMBRAPA (2018). Adaptado por autor (2020).

A vulnerabilidade pedológica (Fig. 9) na BHA é observada em áreas reclassificadas como estáveis $101.261,9 \mathrm{~km}^{2}(26,3 \%)$ e moderadamente estáveis $2.568,0 \mathrm{~km}^{2}(0,7 \%)$ que podem estar relacionadas com o latossolo e a hidrografia respectivamente. A categoria de transição medianamente estável/vulnerável possui 83.602,1 $\mathrm{km}^{2}(21,7 \%)$ de área, sendo provavelmente associada ao argilossolo. As regiões críticas são as classes moderadamente vulnerável $26.376,7 \mathrm{~km}^{2}$ $(6,8 \%)$ e vulnerável 171.016,2 $\mathrm{km}^{2}(44,4 \%)$ caracterizando a maior parte da BHA e possivelmente sob os efeitos do cambissolo, neossolo e plintossolo. A erodibilidade do solo é a susceptibilidade natural pedológica á processos erosivos (Cassol et al., 2018), sendo estudada por Carvalho e Hernani (2001) para o latossolo na região do centro-oeste.
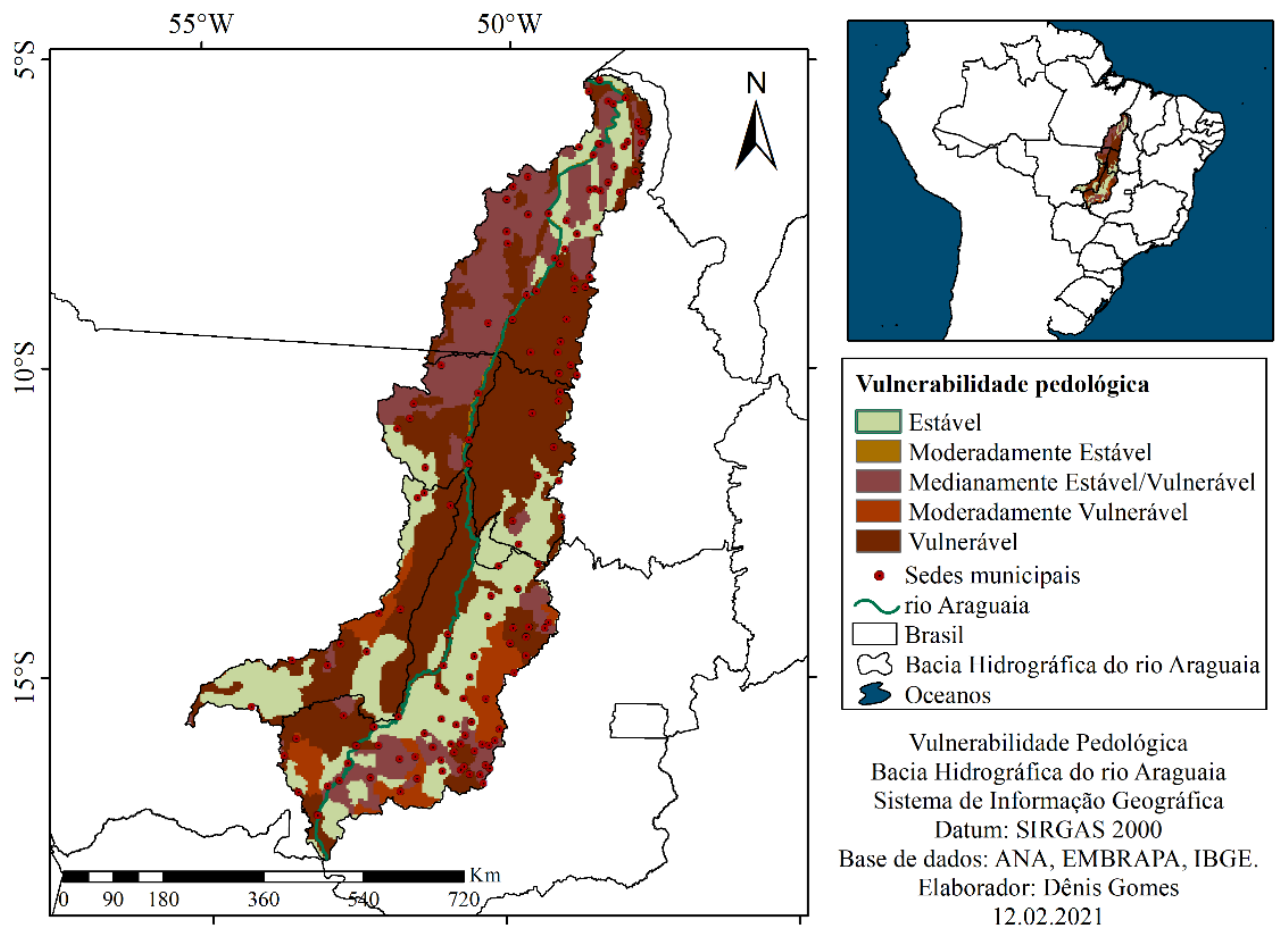

Gomes,D.J.G.C., Sousa, E. V.S., Ferreira, N. S., Lobato, R. R. C., , Ribeiro, B. F., Dias, G. F. M. 
Figura 9. Vulnerabilidade Pedológico: Bacia Hidrográfica do rio Araguaia. Fonte: Autor (2020).

Os critérios usados para as variáveis em estudo (Tab. 2) para a BHA identificou-se as áreas críticas de vulnerabilidade (uso e ocupação da terra, declividade e solo) com valores de 2,5 á 3,0.
As zonas estáveis apresentaram variação de 1,0 a 1,5 e foram adquiridas para todas as classificações com destaque para a precipitação que foi caracterizada pela estabilidade em toda a BHA.

Tabela 2. Critérios adotados para as categorias: Precipitação; Uso e ocupação da terra; Declividade; Solo.

$\begin{array}{ccccc}\begin{array}{c}\text { Vulnerabilidade } \\ (\text { V) }\end{array} & \text { Precipitação } & \begin{array}{c}\text { Uso da } \\ \text { terra }\end{array} & \text { Declividade } & \text { Solo } \\ \begin{array}{c}\text { Vulnerável } \\ \text { Moderadamente } \\ \quad \text { Vulnerável }\end{array} & - & 3,0 & 3,0 & 3,0 \\ \begin{array}{c}\text { Medianamente } \\ \text { Estável/Vulnerável } \\ \text { Moderadamente }\end{array} & - & - & - & 2,5 \\ \quad \text { Estável } & 1,5 & 1,5 & 1,5 & 1,5 \\ \quad \text { Estável } & 1,4 & 1,0 & 1,2 & 1,0 \\ & \text { Fonte: Autor }(2020) . & & \\ & & & & \\ \end{array}$

\section{Erosão hídrica do solo}

A Fig. 10 apresenta a vulnerabilidade à erosão hídrica do solo na BHA. No baixo Araguaia é predominante áreas classificadas como estáveis e moderadamente estáveis, apesar da observação de partes críticas enquadrando-se em moderadamente vulneráveis e vulneráveis nas bordas desta subbacia, possivelmente motivada por fatores pedológicos e clinográficos, além das ações antrópicas no lado oeste. A região do médio Araguaia é marcada pela estabilidade, sendo a parte central apresentando tendências a classe moderadamente vulnerável. Entretanto, á leste no Cantão do Araguaia há domínio de áreas moderadamente vulneráveis com o setor sul na maior parte classificado como estável. Na sub- bacia do rio das Mortes é identificado zonas de transição de moderadamente estáveis á moderadamente vulneráveis, alternando-se ao sul em áreas de estabilidades e vulneráveis, resultado da combinação da susceptibilidade natural com as atividades antropogênicas. $\mathrm{O}$ alto Araguaia possui classes estáveis na maior parte do lado oeste, porém, o leste (sudeste) está comprometido com áreas vulneráveis devido os efeitos da pressão do uso da terra acelerado em solo com alta erodibilidade e superfícies íngremes. Barros et al. (2018) produziu um modelo de erosão hídrica para uma sub-bacia no Alto Araguaia e observou que os principais motivadores são a declividade e principalmente as alterações do uso e ocupação do solo com a pastagem. 


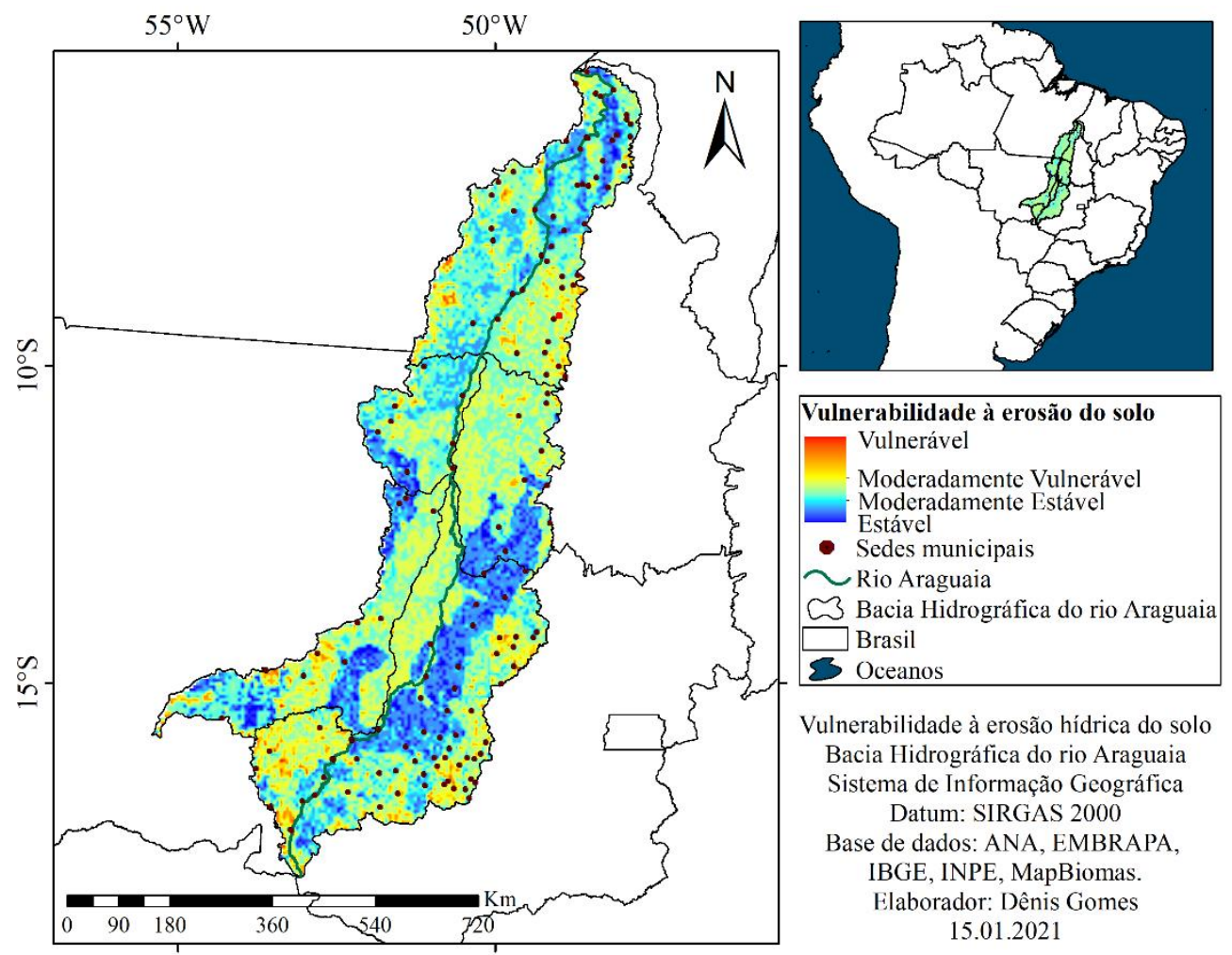

Figura 10. Vulnerabilidade á erosão hídrica do solo: Bacia Hidrográfica do rio Araguaia. Fonte: Autor (2020).

A erosão hídrica do solo promove o carreamento de partículas ricas em nutrientes, diminuindo o potencial de fertilização do solo, além de reduzir a espessura da camada do solo, diminuindo a capacidade de retenção hídrica e culminando no aumento do escoamento superficial da água pluvial agravando ainda mais as etapas dos processos erosivos (Cerdà et al., 2009; Santos et al., 2010). Os pesquisadores ainda reforçam que este desastre natural pode favorecer o surgimento de outros tipos de desastres devido o arraste de sedimentos e produtos agroquímicos que intensifica o assoreamento dos rios, comprometendo a área á risco de enchentes, assim como poluindo a água e o solo respectivamente. Diante da baixa taxa de nutrientes, Han et al. (2019) sugerem que a construção de parcelas agrícolas pode auxiliar na recuperação do solo e diminuir sua vulnerabilidade á erosão.

Em seus estudos, Coe et al. (2011) observaram em uma região da BHA que o aumento das mudanças do uso da terra associado com os elevados volumes pluviais pode promover maiores escoamentos superficiais e consequentemente erosões do solo. Buscando obter informações acerca da conservação ambiental da região do Araguaia, Latrubesse et al. (2019) comentam o quanto prejudicial é a substituição da vegetação primária para áreas destinadas as atividades agrícolas, pois favorecem na formação de erosão.
Muitos trabalhos abordam a erosão do solo em diversos aspectos como Mohammed et al. (2020) que detectou a influência de diferentes declives nesse fenômeno do solo, Colman et al. (2019) que observou os efeitos do clima associado com as mudanças do uso e cobertura da terra provoca processos erosivos principalmente em áreas com atividades agrícolas. Silva et al. (2019) desenvolveu um produto cartográfico que apresenta a vulnerabilidade do solo de uma bacia hidrográfica próxima da BHA, ratificando as linhas de pensamento dos autores anteriores de que o acelerado avanço do uso e ocupação da terra provoca a instabilidade do solo. Neste sentido, cenários futuros (2050) de perda do solo por erosão foram estimados para o Pantanal (bioma adjacente ao que se localiza a BHA) e apontaram que se não houver proteção ambiental regidos por lei em forma de reservas legais para controlar a retirada descontrolada da cobertura vegetal, o equilíbrio da biodiversidade assim como a saúde do solo da região pantaneira pode está sob sérios risco (Guerra et al., 2020).

Segundas informações do SNPDC (2020) algumas cidades como Aruanã (2006), Água Boa (2007-2008) e Novo Santo Antônio (2009) decretaram Situação de Emergência (SE) devido a ocorrência de vários de tipos de erosões (fluviais e Continentais) em zonas de transição (medianamente estáveis/vulneráveis). 


\section{Conclusões}

Na escala climatológica, a precipitação não atua de forma significativa na erosão do solo da BHA. No entanto, constatou-se que o avanço do uso e ocupação da terra, principalmente o destinado a prática do pasto em áreas naturalmente instáveis (declives e solo) como algumas regiões do sulsudeste, é o agravante nos processos erosivos na BHA.

Assim, um sinal de alerta é de suma importância para os municípios de: Abreulândia, Alto Araguaia, Aurilândia, Cachoreira de Goiás, Campinápolis, Campos Verdes, Chapada de Areia, Colméia, Cristalândia, Divinópolis do Tocantins, Dois Irmãos do Tocantins, Dueré, Goianorte, Guiratinga, Itaporã do Tocantins, Ivolândia, Lagoa da Confusão, Marianópolis do Tocantins, Moiporá, Monte Santo do Tocantins, Novo São Joaquim, Paraíso do Tocantins, Pequizeiro, Pium, Santa Rita do Araguaia, Santa Terezinha de Goiás, Santo Antônio do Leste, São João da Paraúna, Tesouro, Uirapuru, Wanderlândia. Para estes locais, medidas conservadoras como a desaceleração do desmatamento devem ser prioridade para a manutenção da saúde do solo, pois amenizaria os efeitos antrópicos acentuados associados com extremos climáticos locais de alta intensidade em regiões com declives e solos que favorecem a instabilidade, prevenindo possíveis casos de erosão no futuro.

\section{Referências}

Agência Nacional das Águas (ANA). Sistema Nacional de Informações sobre Recursos Hídricos. Disponível em: < http://www.snirh.gov.br/hidroweb/publico/apr esentacao.jsf>. Acessado: 01/02/2020.

Agência Nacional das Águas (ANA). Conjecturas dos recursos hídricos no Brasil: regiões hidrográficas brasileiras. Ed. Especial. Brasília, 2015.

Amorim, J. S., Viola, M. R., Junqueira, R., Oliveira, V. A., Mello, C. R., 2020. Evaluation of satlellite precipitation products for hydrological modeling in the Brazilian Cerrado Biome. Water, 12 (2571), 1-18.

Alencar, A., Shimbo, J. Z., Lenti, F., Marques, C. B., Zimbres, B., Rosa, M., Arruda, V., Castro, I., Ribeiro, J. P. F. M., Varela, V., Alencar, I., Piontekowski, V., Ribeiro, V., Bustamente,
M. M. C., Sano, E. E., Barroso, M., 2020. Mapping three decades of changes in the Brazilian Savanna native vegetation using landsat data processed in the Google Earth Engine Plataform. Remote Sensin. 12, (924), $1-23$.

Almagro, A., Oliveira, P. T. S., Nearing, M. A., Hagemann, S., 2017. Projected climate change impacts in rainfall erosivity over Brazil. Scientific Reports, 7 (8130), 1-12.

Almeida, R. F. B., Ferreira Junior, L. G., Bayer, M., 2018. Análise da cobertura e uso da terra da bacia hidrográfica do rio do Coco e suas implicações sobre as áreas de preservação permanente como instrumento na gestão dos recursos hídricos. Revista Desenvolvimento e Meio Ambiente, 49, 60-82.

Ashcorft, L., Karoly, D. J., Dowdy, A. J., 2019. Historical extreme rainfall events in southeastern Australia. Weather and Climate Extremes, 25, 1-12.

Assis, P. C., Bayer, M., 2020. Análise multitemporal do sistema fluvial do rio Araguaia, Aruanã - Goiás, Brasil. Revista de Geografia, 9 (2), 1-18.

Balbinot, R., Oliveira, N. K., Vanzetto, S. C., Pedroso, K., 2008. O papel da floresta no ciclo hidrológico em bacias hidrográficas. Revista Ambiência, 4 (1), 131-149.

Barbosa, F. T., Bertol, I., Werner, R. S., Ramos, J. C., Ramos, R. R., 2012. Comprimento crítico de declives relacionado à erosão hídrica, em três tipos e doses de resíduos em duas direções de semeaduras direta. Revista Brasileira de Ciência do Solo, 36, 1279-1290.

Barbosa, S. G., Spletozer, A. G., Roque, M. P. B., Ferreira Neto, J. A., Dias, H. C. T., Ramos, M. P., Bonilla, M. A. C., Ribeiro, W. S., De la Cruz, R. A., Zanuncio, J. C., 2018. Geotechnolgy in the analysis of forest fragments in northern Mato Grosso, Brazil. Scientific Reports, 3959, 1-7.

Barnes, B., Dunn, S., Wilkinson, S., 2019. Natural hazard, disaster management and simulation: a bibliometric analysis of keyword searches. Natural Hazards, 97, 813-840. 
Barros, E. N. S., Viola, M. R., Rodrigues, J. A. M., Mello, C. R., Avanzi, J. C., Giongo, M., 2018. Modelagem da erosão hídrica nas bacias hidrográficas dos rios Lontra e Manuel Alves Pequeno, Tocantins. Revista Brasileira de Ciências Agrárias, 13 (1), 1-9.

Bayer, M., Assis, P. C., Suizu, T., Gomes, M. C., 2020. Mudanças no uso e cobertura da terra na bacia hidrográfica do rio Araguaia e seus reflexos nos recursos hídricos, o trecho médio do rio Araguaia em Goiás. Revista FrancoBrasileira de Geografia, 48.

Borges, F. J. A., Loyola, R., 2020. Climate and land-use change refugia for Brazilian Cerrado birds. Perspectives in ecology and conservation, 18, 109-115.

Carvalho, M. P.; Hernani, L. C., 2001. Parâmetros de erosividade da chuva e da enxurrada correlacionados com perdas de solo e erodibilidade de um latossolo roxo de Dourados (MS). Revista Brasileira de Ciências do Solo, 25, 137-146.

Carvalho, T. M., Ferreira, M. E., Bayer, M., 2008. Análise intregada do uso da terra e geomorfologia do bioma cerrado: um estudo de caso para Goiás. Revista Brasileira de Geografia Física, 1 (1), 62-72.

Casaroli, D., Rodrigues, T. R., Martins, A. P. B., Evangelista, A. W. P., Alves Jr., J., 2018. Padrões de Chuva e de Evapotranspiração em Goiânia, GO. Revista Brasileira de Meteorologia, 33 (2), 247-256.

Cassol, E. A., Silva, T. S., Eltz, F. L. F., Levien, R., 2018. Soil erodibility under natural rainfall conditions as the $\mathrm{K}$ factor on the universal soil loss equation and application of the nomograph for a subtropical ultisol. Revista Brasileira de Ciências do Solo, 42, 1-12.

Cassol, H. L. G., Arai, E., Sano, E. E., Dutra, A. C., Hoffmann, T. B., Shimabukuro, Y. E., 2020. Maximum fraction images derived from yearbased project for on-board autonomyvegetation (PROBA-V) data for the rapid assessment of land use and land cover areas in Mato Grosso states, Brazil. Land, 9 (139), 120.

Cavalcante, R. B. L., Pontes, P. R. M., SouzaFilho, P. W. M., Souza, E. B., 2019. Opposite effects of climate and land use changes on the anual water balance in the Amazon Arco f deforestation. Water Resources Research, 55, 3092-3106.

Cerdà, A., Flanagan, D. C., Bissonnais, Y. L., Boardman, J., 2009. Soil erosion and agriculture. Soil \& Tillage Research, 106, 107108.

Coe, M. T., Latrubesse, E. M., Ferreira, M. E., Amsler, M. L., 2011. The effects of deforestation and climate variability on the streamflow on the Araguaia river, Brazil. Biogeochemistry, 105, 119-131.

Couto Jr., A., Martins, P., Sano, E., Martins, E., Vieira, L., Salemi, L., Vasconcelos, V., 2021. Data for: Terrain units, land use/cover, and gross primary productivity of the largest fluvial basin in the Brazilian Amazonia/Cerrado ecotone: The Araguaia River Basin. Data in Brief, 34, 1-7.

Crepani, E., Medeiros, J. S., Azevedo, L. G., Hernandez Filho, P., Florenzano, T. G., Duarte, V., 2001. Sensoriamento Remoto aplicado ao zoneamento ecológico-econômico, São José dos Campos: INPE, 25p.

Crepani, E., Medeiros, J. S., Palmeira, A., 2004. F. Intensidade pluviométrica: uma maneira de tratar dados pluviométricos para análise da vulnerabilidade de paisagens à perda de solo. INPE-11237-RPQ/760. São José dos Campos: Inpe.

Colman, C. B., Oliveira, P. T. S., Almagro, A., Soares-Filho, B. S., Rodrigues, D. B. B., 2019. Effects of climate and land-cover change on soil erosion in Brazilian Pantanal. Sustainability, 11, 1-16.

Cuibaiano, M. N., Neves, S. M. A. S., Nunes, C. M., Serafim, M. E., Neves, R. J. 2017. Vulnerabilidade ambiental á erosão hídrica na sub-bacia do Córrego do Guanabara / Reserva do Cabaçal - MT, Brasil. Revista Geociências, 36 (3), $543-556$.

Empresa Brasileira de Pesquisas Agropecuárias (EMBRAPA). Sistema Brasileiro de Classificação de solos (SiBCS). Brasília - DF: EMBRAPA, 2018, 75 p.

Ferreira, R. R. M., Tavares Filho, J., Ferreira, V. M., 2010. Efeitos de sistemas de manejo de 
pastagens nas propriedades físicas do solo. Revista Semina: Ciências Ágrarias, 31 (4), 913-932.

Gao, J., Bai, Y., Cui, H., Zhang, Y., 2020. The effect of diferente crops and slopes on runoff and soil erosion. Water Practice and Technology, 15 (3), 773-780.

Gomes, D. J. C., Ferreira, N. S., Lima, A. M. M., 2019. Tendências de variabilidade espaçotemporal pluviométrica na bacia hidrográfica do rio Araguaia. Revista Enciclopédia Biosfera, 16 (29), 1421-1433.

Gomes, D. J. C., Silva, L. P., Lima, A. M. M., 2020. Vulnerabilidade ambiental na sub-bacia do médio Tapajós (AM-PA). Revista GeoNorte, 11 (38), 71-89.

Gomes, L., Simões S. J. C., Nora, E. L. D., SousaNeto, E. R., Forti, M. C., Ometto, J. P. H. B., 2019. Agricultural expansion in the Brazilian Cerrado: increased soil and nutriente loss and decreased agricultural productivity. Land, 8 (12), 1-26.

Guerra, A., Oliveira, P. T. S., Roque, F. O., Rosa, I. M. D., Ochoa-Quintero, J. M., Guariento, R. D., Colman, C. B., Dib, V., Maioli, V., Strassburg, B., Garcia, L. C., 2020. The importance of Legal Reserves for protecting the Pantanal biome and preventing agricultural losses. Journal of Environmental Management, 260, 1-11.

Han, Z., Zhong, S., Ni, J., Shi, Z., Wei, C., 2019. Estimation of soil erosion to define the slope length of newly reconstructed gentle-slope lands in hilly moutainous regions. Scientific Reports, 9 (4676), 1-11.

Hoque, Y. M., Raj, C., Hantush, M. M., Chaubey, I., Govindaraju, R. S., 2014. How do land-use and climate change affect watershed health? A scenario-based Analysis. Water Quality, Exposure and Health, 6, 19-33.

INMET. Instituto Nacional de Meteorologia Normais Climatológicas. Disponível: http://www.inmet.gov.br/portal/index.php?r=c lima/normaisClimatologicas. Acessado em: 25/01/2020.

Instituto Nacional de Pesquisas Espaciais (INPE). Projeto Topodata (Banco de dados
Geomorfométricos do Brasil). Disponível em: http://www.webmapit.com.br/inpe/topodata/.

Acessado em: 10 de janeiro de 2019.

Ionita, I., Fullen, M. A., Zglobicki, W., Poesen, J., 2015. Gully erosion as a natural and humaninduced hazard. Natural Hazards, 79, 1-5.

Katarine, K., Lemes, M. M. D. D., Andrade, M., Queiroz, S. J., 2014. Os desastres naturais e seus impactos a saúde pública brasileira. Revista Estudos, 41 (2), 307-313.

Latrubesse, E. M., Arima, E., Ferreira, M. E., Nogueira, S. H., Wittmann, F., Dias, M. S., Dagosta, F. C. P., Bayer, M., 2019. Fostering water resourse governance and conservation in the Brazilian Cerrado biome. Conservation Science and Practice, 1, 1-8.

Lee, E., Livino, A., Han, S. C., Zhang, K., Briscoe, J., Kelman, J., Moorcroft, P., 2018. Land cover change explains the increasing discharge of the Paraná River. Regional Environmental Change, 18, 1871-1881.

Leite, M. H. S., Couto, E. G., Amorim, R. S. S., Scaramuzza, J. F., 2018. Loss of water and nutrientes in diferente soil tillage systems subjected to natural rainfall in the state of Mato Grosso, Brazil. Engenharia Agrícola, 38 (6), 864-873.

Lense, G. H. E., Parreiras, T. C., Moreira, R. S., Avanzi, J. C., Mincato, R. L., 2019. Estimates of soil losses by the erosion potential method in tropical latosols. Ciência e Agrotecnologia, 43, 1-10.

Maciel, A. M., Picoli, M. C. A., Vinhas, L., Camara, G., 2020. Identifying land use change trajectories in Brazil's Agricultural frontier. Land, 9 (506), 1-16.

Mata-Lima, H., Alvino-Borba, A., Pinheiro, A., Mata-Lima, A., Almeida, J. A., 2013. Impactos dos desastres naturais nos sistemas ambientais e socioeconômico: o que faz a diferença? Revista Ambiente \& Sociedade, 16 (3), 45-64.

Matule, E. D., Macarringue, L. S., 2020. Avaliação da vulnerabilidade à perda de solo no distrito de Boane em Moçambique. Revista Sociedade \& Natureza, 32, 225-235.

Gomes,D.J.G.C., Sousa, E. V.S., Ferreira, N. S., Lobato, R. R. C., , Ribeiro, B. F., Dias, G. F. M. 
Merten, G. H., Minella, J. P. G., 2013. The expansion of Brazilian agriculture: soil erosion scenarios. International Soil and Water Conservation Reseach, 1 (3), 37-48.

Mendes, A. T., 2018. Delimitação da bacia hidrográfica do rio Santo Antônio pela ferramenta de delimitação automática TauDEM. Revista Brasileira de Geografia Física, 11 (3), 973-986.

Ministério do Meio Ambiente (MMA). Caderno da Região Hidrográfica do Tocantins-Araguaia. Brasília, 2006.

Ministério do Meio Ambiente (MMA). Conselho Nacional de Recursos Hídricos. Resolução n. 32, de 15 de Outubro de 2003. Disponível em. http://www.ceivap.org.br/ligislacao/Resol ucoes-CNRH/Resolucao-CNRH\%2032.pdf. Acesso em: 01/05/2020.

Mohammed, S., Abdo, H. G., Szabo, S., Pham, Q. B., Holb, I. J., Linh, N. T. T., Anh, D. T., Alsafadi, K., Mokhtar, A., Kbibo, I., Ibrahim, J., Rodrigo-Comino, J. Estimating human impacts on soil erosion considering diferente hillslop inclinations and land uses in the coastal region of Syria. Water, 12, 1-20.

Moreira, V. B., Perez Filho, A., 2020. Das superfícies de aplainamento aos pulsos climáticos holocênicos: a evolução da paisagem em relevos de chapada. Revista Sociedade \& Natureza, 32, 176-195.

Oliveira, E. G., Ferreira, M. E., Araújo, F. M., 2012. Diagnóstico do uso da terra na região centro-leste de Minas Gerais, Brasil: a renovação da paisagem pela cana-de-açúcar e seus impactos socioambientais. Revista Sociedade \& Natureza, 24 (3), 545-556.

Orozco, I., Martínez, A., Ortega, V., 2020. Assessment of the water, environmental, economic and social vulnerability of a watershed to the potential effects of climate change and land use change. Water, 12 (6), 121.

Panagos, P., Borrelli, P., Poesen, J., Ballabio, C., Lugato, E., Meusburger, K., Montanarella, L., Alewell, C., 2015. The new assessment of soil loss by water erosion in Europe. Environmental Science \& Policy, 54, 438-447.
Peixoto, C. S., Silva, C. A., Mattos, S. H. V. L., Boin, M. N., 2018. Fragilidade potencial e emergente no município de Ivinhema (MS). Revista Eletrônica da Associação dos Geógrafos Brasileiros-Seção Três Lagoas /MS, 27 (15), 9-30.

Pereira, J. S. Avaliação das perdas de solos por erosão laminar na área de influência da UHE Amador Aguiar I, 2014. 18p. Dissetação (Mestrado em Geografia). Programa de PósGraduação em Geografia. Universidade Federal de Uberlândia, Uberlândia, 2014.

Pasinato, A., Cunha, G. R., Fontana, D. C., Monteiro, J. E. B. A., Nakai, A. M., Oliveira, A. F., 2018. Potential área and limitations for the expansion of rainfed wheat in the Cerrado biome of Central Brazil. Pesquisa Agropecuária Brasileira, 53 (7), 779-790.

Peron, A. J., Evangelista, A. R., 2004. Degradação de pastagens em regiões de cerrado. Revista Ciência Agrotecnológica, 28 (3), 655-661.

Piacentini, T., Galli, A., Marsala, V., Miccadei, E., 2018. Analysis of soil erosion induced by heavy rainfall: a case study from the NE abruzzo hills área in central Italy. Water, 10 (1314), 1-29.

Pires, M. O., 2020. 'Cerrado' old and new agricutural frontiers. Brazilian Political Science Review, 14 (3), 1-24.

Prina, B. Z., Tretin, R., Alvarez, J. W. R., Pellegrini, A., 2016. Mapeamento de declividade de uma sub-bacia hidrográfica mediante comparação de bases cartográficas. Revista Geografia, Ensino \& Pesquisa, 20 (2), 125-134.

Projeto MapBiomas. 2018 - Coleção 4.1 da série anual de mapas de cobertura e uso do solo do Brasil. Disponível: https://mapbiomas.org/. Acesso: 08/02/2020.

Rabelo, C. G., Ferreira, M. E., Araújo, J. V. G., Stone, L. F., Silva, S. C., Gomes, M. P., 2009. Influência do uso do solo na qualidade da água no bioma cerrado: um estudo comparativo entre bacias hidrográficas no Estado de Goías, Brasil. Revista Ambiente \& Água, 4 (2), 172187. 
Reis, A. A., Fernandes, W. S., Ramos, M. H., 2020. Avaliação de duas fontes de dados de precipitação com especial interesse para produção hidrelétrica no Brasil. Revista Brasileira de Recursos Hídricos, 25 (14), 1-16.

Santos, G. G., Griebeler, N. P., Oliveira, L. F. C., 2010. Chuvas intensas relacionadas à erosão hídrica. Revista Brasileira de Engenharia Agrícola e Ambiental, 14 (2), 115-123.

Sartori, M., Philippidis, G., Ferrari, E., Borrelli, P., Lugato, L., Montanarella, L., Panagos, P., 2019. A linkage between the biophysical and the economic: Assessing the global Market impacts of soil erosion. Land Use Policy, 86, 299-312.

Secretaria Nacional de Proteção e Defesa Civil (SNPDC). Sistema Integrado de Informações sobre Desastres Naturais (S2iD). Disponível em: https://s2id.mi.gov.br/. Acessado em: 07/04/2020.

Serrão, E. A. O., Santos, C. A., Wanzeler, R. T. S., Gonçalves, L. J. M., Lima, A. M. M., 2015. Avaliação da seca de 2005 e 2010 na Amazônia: análise da bacia hidrográfica do rio Solimões. Revista Geográfica Acadêmica, 9 (2), 5-20.

Serrão, E. A. O., Silva, M. T., Ferreira, T. R., Silva, V. P. R., Sousa, F. S., Lima, A, M. M., Ataide, L. C. P., Wanzeler, R. T. S., 2020. Land use change scenarios and their effects on hydropower energy in the Amazon. Science of the Total Environment, 744.

Sidle, R. C., Taylor, D., Lu, X. X., Adger, W. N., Lowe, D. J., Lange, W. P., Newnham, R. M., Dodson, J. R., 2004. Interactions of natural hazards and society in Austral-Asia: evidence in past and recente records. Quaternary International, 118/119, 181-203.

Silva, A. S., Rosa, R., 2019. Mapa de capacidade e potencial do uso da terra do município de Catalão (GO). Caderno de Geografia, 29 (59), 954-977.

Silva, B. A., Giongo, P. R., Martins, P. T. A., Barbosa, T. A., Moraes, V. H., Cavalcante, T. J., Giongo, A. M. M., 2019. Soil erosion vulnerability in the sourthern parto $f$ the Meia Ponte watershed, Goias, Brazil. IDESIA (Chile), 37 (2), 81-86.
Shanshan, W.; Baoyang, S.; Chaodong, L.; Zhanbin, L.; Bo, M. Runoff and soil erosion on slope cropland: A review. Journal of Resources and Ecology, v. 9, n. 5, p. 461-470, 2018.

Souza Jr., C. M., Shimbo, J. Z., Rosa, M. R., Parente, L. L., Alencar, A. A., Rudorff, B. E. T., Hasenack, H., Matsumoto, M., Ferreira, L. G., Souza-Filho, P. W. M., Oliveira, S. W., Rocha, W. F., Fonseca, A. V., Marques, C. B., Diniz, C. G., Costa, D., Monteiro, D., Rosa, E. R., Vélez-Martin, E., Weber, E. J., Lenti, F. E. B., Paternost, F., Pareyn, F. G. C., Siqueira, J. V., Vieira, J. L., Ferreira Neto, L. C., Saraiva, M. M., Sales, M. H., Salgado, M. P. G., Vasconcelos, R., Galano, S., Mesquita, V. V., Azevedo T., 2020. Reconstructing three decades of land use and land cover changes in Brazilian biomes with landsat archive and Earth Engine. Remote Sensing, 12 (2735), 127.

Sposito, G., 2013. Green water and global food security. Vadose Zone Journal, 12, 1-6.

Stroosnijder, L., 2007. Rainfall and land degradation. In: Sivakumar, M. V. K., Ndiang'ui. (eds.) Climate and land degradation. Environmental Science and Engineering (Environmental Science). Springer, Berlin, Heidelberg.

Tadesse, L., Suryabhagavan, K. V., Sridhar, G., Legesse, G., 2017. Land use and land cover changes and soil erosion in Yezat Watershed, North Western Ethiopia. International Soil and Water Conservation Research, 5, 85-94.

Telles, T. S., Guimarães, M. F., Dechen, S. C. F., 2011. The costs of soil erosion. Revista Brasileira de Ciência do Solo, 35 (32), 287298.

Tiburan Jr., C., Saizen, I., Kobayashi, S., 2013. Geospatial-based vulnerability assessment of na urban watershed. Procedia Environmental Sciences, 17, 263-269.

Tominaga, L. K.; Santoro, J.; Amaral, R. Desastres naturais: conhecer para prevenir. Ficha catalográfica elaborada pela biblioteca do Instituto Geológico. São Paulo, 2009.

Vanwalleghem, T., Gómez, J. A., Amate, J. I., Molina, M. G., Vanderlinden, K., Guzmán, G.,

Gomes,D.J.G.C., Sousa, E. V.S., Ferreira, N. S., Lobato, R. R. C., , Ribeiro, B. F., Dias, G. F. M. 
Laguna, A., Giráldez, J. V., 2017. Impact of historical land use and soil management change on soil erosion and agricultural sustainability during the anthropocene. Anthropocene, 17, 13-29.

Zamparoni, C. A. G. P., 2012. Riscos e desastres naturais em ambiente urbano: o exemplo de Cuiabá/MT. Revista Brasileira de Climatologia, 10, 7-20. 